\title{
COERÊNCIA NORMATIVA E PRINCÍPIOS NA ARGUMENTAÇÃO JURÍDICA
}

\section{NORMATIVE COHERENCE AND PRINCIPLES IN LEGAL REASONING}

\author{
${ }^{1}$ Francisco José Barrios Jansen Ferreira
}

\section{RESUMO}

Em teorias tradicionais, princípios jurídicos são guias normativos para se mitigar a discricionariedade judicial em casos de indeterminação normativa. Contudo, a falta de critérios de racionalidade na sua aplicação promove a desvalorização do direito democraticamente posto. Sugere-se, através deste artigo, o enfrentamento do problema através do emprego dos princípios no bojo de uma argumentação jurídica fundada na coerência sistemática do direito.

PALAVRAS-CHAVE: Princípios Jurídicos; Coerência. Argumentação Jurídica;. Coerência Normativa. Ponderação

\begin{abstract}
In traditional theories, legal principles are normative guides to mitigate judicial discretion in cases of normative indeterminacy. However, the lack of rational criteria in its application promotes the devaluation of the democratically enacted Law. I intend, and this paper is a means for that purpose, to address the problem through the employ of legal principles in a context of legal reasoning based on the legal system as a coherent whole.
\end{abstract}

KEYWORDS: Legal Principles; Coherence; Legal Reasoning; Legal Coherence. Weight Formula

\footnotetext{
${ }^{1}$ Advogado, pesquisador em Teoria da Argumentação Jurídica e do Direito, Pós-graduando em Direito Processual Civil - ULBRA, Rio Grande do Sul, RS, (Brasil), Aluno não-regular do programa de pós graduação, mestrado acadêmico - Universidade do Vale dos Sinos - UNISINOS, Rio Grande do Sul, RS, (Brasil). E-mail: franciscojansenferreira@gmail.com.
} 


\section{INTRODUÇÃO}

A (crescente) popularidade da expressão "princípio jurídico" nas decisões e na doutrina brasileira, muito embora frequentemente se remeta às produções jurídicas de autores como Ronald Dworkin e Robert Alexy, raramente faz jus às propostas apresentadas pelos referidos. Ao contrário, lança dúvida sobre o conteúdo jurídico, pela falta de critérios de racionalidade e previsibilidade na sua aplicação.

O standard jurídico que, originalmente, serviria para balizar decisões nos casos de indeterminação normativa das regras, orientando o juiz em detrimento de uma decisão discricionária, acaba servindo como um instrumento que permite ao juiz mais liberdade em relação ao direito formalmente e democraticamente estabelecido. Essa perspectiva esvazia a autoridade legislativa e coloca a delimitação do direito predominantemente nas mãos do juiz solipsista, adepto do pan-principiologismo ${ }^{2}$ que lhe garante uma ampla (e ilegítima) liberdade decisória. Cumpre salientar: o problema não está na existência de princípios, mas no emprego irresponsável de standards sem critérios de racionalidade decisória.

Como proposta para revalorizar a forma jurídica e sua legitimidade democrática, propõese dois passos: o resgate da autoridade legislativa, como fonte primária de interpretação dos valores políticos fundamentais da comunidade e a identificação de uma forma aceitável de utilizar-se os princípios na argumentação jurídica e na fundamentação de decisões.

Para atender-se à proposta, na forma do presente artigo, far-se-á introdução à definição de Princípio Jurídico, conforme apresentado no ilustre debate entre Hart e Dworkin. A seguir, proceder-se-á no mapeamento de argumentos ancorados em princípios jurídicos e na coerência e, nesse espectro, a sua comparação analítica ao modelo de ponderação. Pretende-se, dessa forma, verificar uma forma de atribuir racionalidade à aplicação de princípios jurídicos - respeitando-se a autoridade legislativa -, inclusive com a contemplação das hipóteses de conflito. O método é de exposição argumentativa e analítica dos institutos, com sua apreciação crítica no corpo da análise através, predominantemente, de testes lógicos.

\footnotetext{
2 A "verdadeira usina de produção de princípios despidos de normatividade" apontada por Lênio, erguida com a inflação de standards genéricos, amplos e vazios de valor deontológico, permissivos a uma gama incontável de decisões diferentes (e até contrárias) dentro de seu vago caráter axiológico. (STRECK, 2014)
} 
O artigo, portanto, é estruturado da seguinte maneira: em primeiro lugar, far-se-á a exposição do paradigma positivista e das contribuições de Dworkin, analisadas com a perspectiva de MacCormick, para estabelecer que tipo de standard são os princípios jurídicos e como identificá-los através de critérios comuns de reconhecimento; segue-se daí à contextualização dos princípios no corpo de uma teoria da argumentação jurídica calcada na coerência do sistema jurídico, empregada na justificação de decisões, que deverá dar conta de identificar qual o papel dos princípios na justificação das decisões; ao fim, se apresenta uma forma de, pretensamente, enfrentar a aplicação (e a colisão) de princípios na argumentação jurídica - alicerçada em critérios de coerência -, que contemple, concomitantemente, a relação entre princípios e demais argumentos sistemáticos.

\section{PARA ALÉM DO POSITIVISMO, UM SISTEMA DE REGRAS E PRINCÍPIOS JURÍDICOS}

Para que se possa propor critérios de racionalidade na aplicação de princípios jurídicos que diferirá daqueles estabelecidos às regras -, é prudente que se faça, em caráter precedente, a sua delimitação como standard jurídico, inclusive contemplado seu caráter racionalizador. Para tanto, far-se-á exposição do paradigma positivismo descritivo hartiano e do debate estabelecido com Dworkin, especialmente pela perspectiva de MacCormick, uma vez que a proposta final passará por critérios de coerência que foram desenvolvidos no seio de sua teoria da argumentação jurídica.

Em síntese, para Hart, o sistema jurídico compreende um conjunto de normas primárias e secundárias que, respectivamente, regem os deveres das pessoas e atribuem funções a pessoas/instituições para modificar/aplicar normas dessa estrutura normativa. A inter-relação entre essas normas é o que garante a qualidade sistemática ao Direito (MACCORMICK, 2010, p. 35-36). A unidade do sistema, por sua vez, se constitui através de "uma norma secundária que oferece critérios para identificar todas as normas que pertencem a ele e que desse modo estipula o dever de autoridades de observar e fazer vigorar todas as outras" (MACCORMICK, 2009, p. $300)$.

Para que esse sistema exista como tal, ele deve estar em vigor (MACCORMICK, 2010, p. 37 ), sendo reconhecido (aceito), do ponto de vista interno, pelo menos por uma parte dos 
operadores do sistema, como uma norma social compartilhada (MACCORMICK, 2009, p. 300), "outros podem fazê-lo apenas relutantemente e por medo de sanções” (MACCORMICK, 2010, p. 37).

Daí nasce a que foi, por "muito tempo, a mais conhecida das críticas de Dworkin, [...] de que [Hart] apresenta, erradamente, o direito como consistindo apenas em regras de 'tudo-ounada', e ignora [...] os princípios jurídicos" (HART, 1994, p. 321). Entender o ataque de Dworkin exige uma explicação preliminar da distinção que ele faz entre duas espécies de normas, regras e princípios:

Diz Dworkin (1999, p. 24) que a distinção entre regras e princípios é uma distinção lógica, uma vez que, mesmo apontando para decisões, diferem no caráter das orientações que fornecem. As regras são aplicadas como subsunção de maneira disjuntiva (tudo ou nada), ou seja, dados os fatos estipulados pela norma, quando válida, deve ser aplicada na sua totalidade ${ }^{3}$. Já os princípios, como o exemplo de que nenhum homem pode beneficiar-se de injustiça por ele cometida, nunca são absolutos; logo, não estipulam as condições necessárias à sua aplicação nem exigem uma decisão particular. (ALVAREZ, 2015. p. 45)

Dessa maneira, os "princípios são normas ou conjuntos de normas 'racionalizantes"” (MACCORMICK, 2009, p. 304). Isto é, conjuntos de regras podem ser compatíveis com uma norma mais geral, o princípio, que lhes dá sentido. Em contrapartida, essas regras agem como manifestações mais específicas ou concretas do princípio ${ }^{4}$.

Os princípios, portanto, teriam dois aspectos essenciais: o primeiro, de serem regras mais gerais, capazes de racionalizar conjuntos de regras, dando-lhes sentido, de maneira que essas regras se transformam em exemplificações dos princípios; o segundo é o de que os princípios representam objetivos, direitos individuais ou valores, encarados como desejáveis de se manter ou dignos de adesão (HART, 1994, p. 322).

Por desempenharem esse papel (racionalizador) no raciocínio jurídico e nos julgamentos, por esse motivo, a incorporação de princípios na teoria do direito (positivista de Hart) tornaria

\footnotetext{
${ }^{3}$ Dizer que a regra se aplica em caráter "tudo-ou-nada" significa dizer que, em relação aos comportamentos que ela regula, ela deve determinar o comportamento, ou ser afastada completamente. Por exemplo: As crianças somente poderão deixar a sala de aula após as $17 \mathrm{~h} 00$. A incidência de outra regra, que autorize as crianças a deixarem a sala de aula, em caso de incêndio, implica: (a) invalidar a regra anterior; ou (b) incluir uma exceção, em que a regra não terá qualquer eficácia. Isto é, para um caso concreto, ou a regra pode ser aplicada de forma válida, ou ela não se aplica e em nada contribui para a decisão (DWORKIN, 2002, p. 39-40).

${ }^{4}$ MacCormick não faz a distinção entre regras e princípios, no trecho referido, trabalhando até então com a ideia "norma mais geral" e "norma menos geral", enquanto trata de "argumentos de princípios" (MACCORMICK, 2009, p. 197).
} 
insustentável a descrição de um sistema jurídico que admita discricionariedade (HART, 1994, p. 321), que permita ao juiz ir fora do direito válido para buscar a resposta à questão que nele não estivesse claramente contida ${ }^{5}$. A discricionariedade estaria, portanto, rechaçada pela existência de "outros fundamentos que gozariam de 'força gravitacional' suficiente para guiar uma decisão, mesmo nos casos duvidosos" (MOTTA, 2014. p. 107).

A resposta de Hart está amparada no argumento central de que regras e princípios se distinguem somente em uma questão de grau, e nega que o seu sistema seja composto exclusivamente de regras "tudo-ou-nada" ou de regras "quase conclusivas", comportando tanto regras mais quanto menos gerais (estas últimas menos conclusivas). Reconhece, no entanto, que os argumentos retirados dos "princípios" constituem um importante elemento da decisão e do raciocínio jurídico, e que foi um erro não ter enfrentado, em sua teoria, a eficácia não conclusiva dessa espécie normativa. (HART, 1994, p. 325).

É prudente apontar que, no Brasil, o uso da expressão princípio jurídico tornou-se de constante uso na doutrina e nos tribunais, popularizada por uma leitura (frequentemente indireta) de autores como Robert Alexy ${ }^{6}$ e o próprio Ronald Dworkin. Ironicamente, o instituto que, em uma doutrina mais tradicional, serviria para estabelecer critérios nacionalizantes, capazes de dar "unidade orgânica para o sistema jurídico" (ENGELMANN, 2001, p. 133), e limitadores da discricionariedade judicial, no Brasil é recebido como um instrumento que amplia a liberdade judicial face à lei e ao direito posto. Como uma forma de driblar dificuldades impostas por normas complexas e/ou que destoam das concepções de justiça do juiz ou do escritor (MICHELON, 2009, p. 1).

Com essa apresentação preliminar, que permite situar os princípios em uma teoria do direito e, simultaneamente, apresentar seus aspectos fundamentais enquanto standards com caráter deontológico, carga axiológica e, sobretudo, função racionalizante de conjuntos normativos, pode-se seguir a dois aspectos importantes relacionados à adoção de princípios em um ordenamento: (a) a verificação de critérios para a identificação de princípios jurídicos (e sua

\footnotetext{
5 "Se nenhuma resposta à questão parece contida no direito em vigor, então o julgamento do caso é remetido ao poder discricionário do juiz". (RICOUR, 2008, p. 156). "Kelsen afirma que o órgão jurídico pode realmente criar uma nova norma que está além da 'moldura' dada pela norma superior." ("Kelsen is stating that the legal organ canactually create a new norm which goes beyond the "frame" given by the superior norm") (MICHELON, 2010. p. 3).

${ }^{6} \mathrm{O}$ presente trabalho não endossa o método de ponderação alexiano. Por sua vez, fará impugnação tangencial ao seu método, contemplando como proposta uma outra possibilidade: a argumentação calcada na coerência para a aplicação de princípios jurídicos e, inclusive, para a solução desses peculiares conflitos normativos.
} 
distinção de princípios meramente morais ou políticos); e (b) o desenvolvimento de uma estrutura de critérios argumentativos para a aplicação desses princípios, que seja leal à autoridade legislativa.

As tarefas não são simples, posto que a primeira desafia os limites do positivismo jurídico adotado como base e a segunda envolve a adoção de elementos de argumentação sistêmica (derivados de critérios de coerência normativa), estes a serem desenvolvidos nos tópicos seguintes.

Com esse ponto de partida, alerta-se que os princípios serão tratados aqui de forma diferente da doutrina jurídica predominante. Não como objetivos do sistema ou meros informadores de valores morais/políticos subjacentes ao ordenamento (e que são conhecidos a esmo por julgadores de insight privilegiado), mas como normas jurídicas similares às regras, senão pela sua mais ampla generalidade. Seu espectro de aplicação, contudo, ficará adstrito e será conhecido através da função racionalizadora que, esta sim, excede aquelas comuns às demais regras e standards normativos.

\section{A IDENTIDADE DO DIREITO DIANTE DA DIMENSÃO MORAL DOS PRINCÍPIOS}

Quando Hart (1994) afirma (e ele afirma) que princípios e regras se distinguem meramente em grau (de generalidade), presume-se que eles obedeceriam aos mesmos critérios de validade que as demais normas. De acordo com Dworkin, no entanto, os princípios jurídicos, “embora genuinamente legais, não são identificáveis por 'pedigree' [“"não podem ser submetidos a um teste"'] (DWORKIN, 2002, p. 58) por meio da norma de reconhecimento" (MACCORMICK, 2009, p. 301).

Se os princípios constituem direito, mas não podem ser identificados através desse critério, a doutrina amparada na regra de reconhecimento precisaria ser modificada ou abandonada (DWORKIN, 2002, p. 63-64). Inclusive, a própria palavra "validade" parece, segundo Dworkin, não ser um termo adequado para definir os princípios, pois trata-se de um termo "tudo ou nada", adequado às regras (não existe algo mais ou menos válido). (DWORKIN, 2002, p. 65-66).

A resposta hartiana é a de que a regra de reconhecimento é suficiente para conceber os

Revista de Teorias da Justiça, da Decisão e da Argumentação Jurídical e-SSN: 2525-9644|Curitiba|v.2 |n. 2|p.133-157| Jul/Dez. 2016. 
"princípios", e que a distinção entre princípios jurídicos e não jurídicos estaria sujeita à mesma forma convencional de consenso judicial (HART, 1994, p. 329). Isto é, sujeita a uma análise dos enunciados internos de deferência a normas (como os princípios) por parte dos funcionários do sistema.

Ainda que a regra de reconhecimento sirva para "reconhecer" a existência de um princípio, como diferenciar uma prática moralmente obrigatória de uma prática juridicamente obrigatória, que deva ser sancionada pelo direito (DWORKIN, 2002, p. 67-68)? Cabe lembrar, que os enunciados internos (de aceitação) consistem "em uma atitude crítica reflexiva [vista como justificada pelos "cidadãos"] em relação ao comportamento previsto pela regra" (BARZOTTO, 1999, p. 110), que muito bem poderia existir em relação a uma norma de cunho moral (e não jurídico).

Esse problema se relaciona, mas não está diretamente ligado às concepções de direito conflitantes entre autores em debate: Em Dworkin, todas as proposições sobre o direito têm uma dimensão moral e dependem de um juízo moral, isto é, o direito só é direito, se decorrer de um conjunto de princípios que representa a melhor justificação moral de um sistema jurídico (HART, 1994, p. 332). Hart, de outro lado, reivindica que a proximidade entre o direito e a moral, e a possibilidade de o direito incorporar elementos morais, inclusive como critério de reconhecimento, não fere a sua autonomia (HART, 1994, p. 331-333).

Entende-se que "ninguém em pleno uso das faculdades mentais - e há pelo menos alguns positivistas em pleno uso das faculdades mentais - jamais sugeriu ou sugeriria que a própria lei seja isenta de valores", mas mesmo que os valores morais não sejam necessários para saber que a lei existe (ou qual lei existe), tampouco para descrevê-la (MACCORMICK, 2009, p. 305), o problema persiste: Como distinguir enunciados normativos morais, daqueles jurídicos, através dos critérios disponíveis de reconhecimento ${ }^{8}$ ?

\footnotetext{
${ }^{7}$ Em verdade, a conclusão/resposta de Hart vai além, observando que o proprio Dworkin oferece uma forma análoga de reconhecimento: "muito do que Dworkin diz acerca dessa matéria parece apoiar o ponto de vista de que, para a sua identificação, é necessário algo muito semelhante a uma regra de reconhecimento que identifique as fontes de direito de forma autorizada, como se descreveu neste livro" (HART, 1994, p. 53. p. 328-329). Por questão de delimitação objetiva, essa análise (de uma regra de reconhecimento dworkiniana) não será levada adiante.

${ }^{8}$ Daqueles recursos de reconhecimento expostos, do positivismo de Hart, segundo o qual a validade das normas do ordenamento se verifica através de cadeias de validade, subordinada a uma regra de reconhecimento. Isto é, a norma pode ser promulgada pelos métodos previstos nas regras do sistema, e que se subordinam a uma regra de reconhecimento (regra última do sistema), ou pode ser reconhecida socialmente, como a incorporação dos costumes ao quadro de regras sociais válidas do direito - uma manifestação social da própria regra de reconhecimento, que não se comunica com cada regra apenas de forma escalonada e hierárquica, mas direta e individualmente com cada outra norma do ordenamento.
} 
Dworkin concordaria que a aceitação espontânea de um princípio político, por parte de um grupo, não implica sua automática transformação em um princípio de direito. Nesse caso, ele pode ser adotado como lei por meio da promulgação da legislação apropriada. Por outro lado, ainda sobre o reconhecimento de princípios, MacCormick propõe que, em virtude da proximidade da proximidade entre direito, moral e política, “devemos acolher calorosamente a vigorosa afirmação de Dworkin dessa verdade, sem necessariamente admitir que o 'positivismo' nos levaria a uma suposição diferente", de fato, novos princípios são incorporados no direito, ora pela legislação, ora pelo processo decisório judicial, que denota seu reconhecimento como direito. (MACCORMICK, 2009, p. 307-309).

Se os princípios políticos/morais são "eventualmente" incorporados ao direito, quando se pode dizer que eles têm a qualidade jurídica? A resposta pode ser encontrada na função sua função racionalizadora. O princípio em questão serve para justificar ou explicar a lei válida ${ }^{9}$ (ou um conjunto de normas válidas) da forma como ela já está estabelecida? Se sim, grandes indícios $^{10}$ de que ele é, de fato, jurídico (MACCORMICK, 2009, p. 310-311). Essa abordagem analítica não deve ser dissociada da abordagem do aspecto hermenêutico/interno da norma ${ }^{11}$. Sem a primeira, não se tem uma norma jurídica; sem a segunda, não se tem uma norma obrigatória. Concomitantemente, essa solução para o problema preserva a identidade do direito diante da moral e da política, porque sujeita a atribuição de juridicidade aos seus critérios autônomos de reconhecimento, sem que isso destrua o seu caráter político ou moral.

Isto é, os princípios, sejam detentores de valor moral ou político, ao atenderem aos critérios ordinários de reconhecimento, passam a ter, adicionalmente, caráter jurídico, de maneira que podem ser normas morais ou políticas, autonomamente, ou jurídicas, ou ambas as coisas (MACCORMICK, 2009, p. 311).

\section{PRINCÍPIOS JURÍDICOS NO CONTEXTO DA ARGUMENTAÇÃO SISTÊMICA}

\footnotetext{
${ }^{9}$ Nesse sentido, o princípio acaba por servir, axiologicamente, como ponte entre direito e justiça (ENGELMANN, 2001, p. 92).

${ }^{10}$ Fala-se em "grandes indícios" porque, como observa MacCormick, muito embora exista "uma diferença entre princípios que são e princípios que não são de caráter jurídico, [ela está] sujeita a uma terra incognita intermediária em que os princípios lutam pelo reconhecimento jurídico" (MACCORMICK, 2009, p. 311).

${ }^{11}$ Os operadores do direito se referem a esse princípio como obrigatório?
} 
Apresentada a delimitação dos princípios jurídicos e os seus critérios de reconhecimento, no bojo deste trabalho, o próximo passo lógico consiste na sua aplicação na justificação de decisões/argumentos e, da mesma maneira, da sua contextualização como elemento de um ramo de argumentação sistêmica - isto é, de racionalização do Direito como um todo coerente, no qual os princípios, através de sua função racionalizadora, remetem-se à autoridade legislativa sem, como é feito na práxis jurídica brasileira, sabotá-la.

Interpretar sempre envolve contextualizar; no tempo, na história, na sociedade, etc. Para as normas, existe sempre um contexto legal para cada material jurídico dotado de autoridade, e a lei é inevitavelmente um elemento do sistema jurídico como todo. Assim, os argumentos sistêmicos são aqueles que apresentam uma compreensão aceitável do texto visto como parte de um sistema jurídico. (MACCORMICK, 2008, p. 169-170).

Uma primeira forma de argumentação sistêmica é baseada na "harmonização contextual", segundo a qual cada norma deve ser analisada em um contexto mais amplo, da lei inteira, ou de um conjunto de leis relacionadas, de maneira que o contexto dê uma base de sentido aos termos utilizados. O mesmo critério se aplica a"argumentos conceituais". Quando o direito positivo incorpora elementos de carga conceitual doutrinária ${ }^{12}$ (ilícito, propriedade, emprego etc.), é justificado que se argumente em consideração pela consistência desse conceito através das normas de um ramo do direito.

Uma segunda forma de argumentação sistêmica é aquela "a partir de precedentes". Essa argumentação tenta identificar quais aspectos de um (ou mais) caso(s) anterior(es) são simultaneamente vinculantes e persuasivos, de maneira que a nova decisão deverá se adequar ao corpo estável de decisões orientadas em um mesmo sentido. Critério semelhante ampara a argumentação "por analogia". Se um enunciado normativo for significativamente análogo a uma disposição similar de outras leis, ou outro código, há um bom fundamento para que a interpretação siga essa analogia, tratando-se o sentido do dispositivo em questão de maneira uniforme à analogia invocada, que às vezes poderá ter o sentido de seus termos originários estendidos ou alterados. Essa forma argumentativa poderá incorporar elementos daquela por precedentes quando esses servirem para demonstrar interpretações anteriores sobre os termos da norma análoga ou da analogia em si.

\footnotetext{
${ }^{12}$ Ilicitude penal, por exemplo, não é a mesma ilicitude civil ou contratual.
} 
Uma terceira forma de argumentação sistêmica é a partir de "princípios gerais" $"$. Na dúvida sobre o sentido de uma norma, deve-se favorecer a interpretação que melhor se adeque ao princípio que rege a questão. Havendo conflito entre eles ${ }^{14}$, será necessário demonstrar a prioridade de um em detrimento do outro, no contexto do caso em análise.

Os argumentos sistêmicosespécies - que não foram expostos de maneira exaustiva podem ser combinados nas suas várias formas e tendem a ser amparados por um ideal geral de coerência, uma vez que sistemas jurídicos normalmente não comportam compromissos únicos ou isolados de princípios e/ou determinação de políticas. Ao invés disso, comportam uma multiplicidade de normas de muitas espécies, que exprimem uma pluralidade de princípios e decisões políticas públicas. Essa qualidade, de respeitar a coerência racional e a inteligibilidade do Direito, enquanto instituição concreta, dá à argumentação sistêmica um valor objetivo importante para a justificação jurídica. (MACCORMICK, 2008, p. 171-175).

\section{COERÊNCIA, PRINCÍPIOS E ANALOGIAS}

Entre as formas de argumentação sistêmica apresentadas, são oportunamente retomadas aquelas formas de argumentos de interpretação com base em princípios e com base em analogias. Segundo essas formas argumentativas, diante da incerteza normativa, poder-se-ia recorrer a um princípio, norma mais geral que a regra geradora de dúvidas, para ali identificar uma orientação sobre o sentido da regra. De outro lado, a analogia é uma regra com um nicho de aplicação semelhante ao do caso em questão (e provavelmente de finalidade similar, regida por princípios similares), que sugere que a aplicação da norma duvidosa poderia se dar de forma similar, análoga.

Essas duas formas argumentativas têm seu poder justificatório amparado na pressuposição de que o sistema jurídico deveria "fazer sentido", enquanto conjunto normativo, demandando-se certa coerência na interpretação das normas jurídicas, notadamente nos casos em que não existe solução clara nos textos normativos relevantes, ou que a solução a solução "obviamente" decorrente do material normativo relevante não pode ser explicada de forma

\footnotetext{
${ }^{13}$ Fala-se aqui apenas da interpretação de normas com base em princípios jurídicos, que se distingue de justificar uma decisão com base em princípios jurídicos. Essa propriedade ampla dos princípios será explorada detidamente em tópico próprio.

${ }^{14}$ Uma forma de lidar com o conflito entre princípios também será tratada em tópicos seguintes.
} 
coerente, ou livre de absurdos. (MICHELON, 2009, p. 9).

Assim, uma análise da coerência servirá como base teórica e naturalmente contextualizará princípios e analogias, dando-lhes sua função no âmbito desta teoria do arrazoamento decisório.

\subsection{COERÊNCIA NORMATIVA}

A coerência é um instrumento que pode ser invocado para verificar a adequação sistêmica de proposições de direito ou de fatos e, na teoria de MacCormick, realmente assume formas diferentes para a sua aplicação em uma ou outra esfera. Seja no contexto de uma coerência normativa ou no de coerência narrativa (de fatos postos ao longo de um corte de tempo), a coerência é uma verificação de proposições que "fazem sentido" (MACCORMICK, 2008, p. 247).

A coerência se distingue da consistência, na medida em que esta última é satisfeita pela mera não contradição entre um número de proposições. Em outras palavras, "um grupo de proposições é mutuamente consistente se cada uma puder ser, sem contradição, afirmada em conjunto com cada uma das outras e com a conjunção de todas as outras". A coerência, por sua vez, não se satisfaz pela não contradição. Para algo ser coerente, deve fazer sentido em sua totalidade e, como a coerência é uma questão de grau, pode permitir algumas inconsistências internas (que podem ser identificadas por recurso à coerência) (MACCORMICK, 2008, p. 248).

Ambas as formas de coerência - narrativa e normativa - integram, em importância concorrente (MACCORMICK, 2008, p. 298), as discussões jurídicas e, consequentemente, os argumentos de justificação de interpretações e decisões, seja para determinar interpretações normativas compatíveis com o ordenamento jurídico (coerência normativa), ou para determinar o que de fato ocorreu, em um conflito de versões fáticas entre partes litigantes, através de inferências com base em provas (coerência narrativa) (MACCORMICK, 2008, p. 248) ${ }^{15}$. O papel desta última para a identificação de normas, contudo, é menor que o da coerência

\footnotetext{
${ }^{15}$ É prudente sinalar que o direito é um ente (existe no tempo) que se transforma através do tempo analítico, formando uma espécie de história, que também deve ser dotada de certa coerência (um ponto de interseção entre coerência normativa e narrativa). Dworkin apresenta essa característica do direito pela metáfora de um romance em cadeia, cuja interpretação deve ter um poder explicativo geral dos aspectos estruturantes da história (DWORKIN, 2002, p. 277). Como exigência da coerência, nesse sentido, o direito, como todo e suas interpretações, através das decisões jurídicas, deve exibir alguma constância, na forma de uma resistência a mudanças repentinas e radicais (MACCORMICK, 2008, p. 304-307).
} 
normativa, esta suficiente para subsidiar a presente proposta. Destarte, esta exposição limitar-seá à coerência normativa.

Por sua vez, a coerência normativa é sistêmica, e sua verificação se dá quando, em um conjunto de regras, todas elas satisfazem ou são concretizações de um princípio mais geral. Não basta a consistência, pois regras não contraditórias podem não fazer sentido entre si. $\mathrm{O}$ importante é observar que essas regras "não fazem sentido se não há nenhum valor ou grupo de valores comuns aos quais essas leis sirvam”. (MACCORMICK, 2008, p. 249-250 e 299).

No contexto apresentado, esses valores são "estados de coisas cuja busca é legítima, desejável, valiosa ou mesmo (a escala ascende gradualmente) obrigatória, na condição de propósitos, objetivos ou fins". Para cada valor, há um princípio segundo o qual esse valor pode, deve ou necessita ser perseguido/realizado. Observar princípios é um meio intrínseco, não meramente instrumental, de alcançar esses valores (MACCORMICK, 2008, p. 251).

Se a coerência depende que as regras façam sentido, ao se voltarem para fins comuns, os princípios, que fornecem orientação sobre busca de valor no contexto de comportamentos regulados por regras, são evidentes fontes de sentido e coerência para conjuntos normativos (MACCORMICK, 2008, p. 252).

Os princípios, assim, englobam áreas do direito, cujas regras passam a ser entendidas como determinações ou concretizações daqueles, ofertando efeito jurídico ${ }^{16}$ a esses princípios que podem ou não fazer parte do material jurídico existente ${ }^{17}$. Novas soluções (um juiz decidindo em face de uma omissão legislativa, por exemplo), são coerentes com o Direito preexistente na medida em que são, conjuntamente com outras regras, determinações ou concretizações desses princípios, que devem fazer parte da justificação da solução (MACCORMICK, 2008, p. 261). É importante que se observe como, sutilmente, o tema se volta para um aspecto da discricionariedade judicial: se um juiz dará solução, a uma lacuna ${ }^{18}$, que

\footnotetext{
${ }^{16}$ Visto anteriormente, sob o o tópico "A identidade do direito diante da dimensão moral dos princípios", que o efeito jurídico é um indicativo da juridicidade do princípio.

${ }^{17}$ Dá-se ênfase e prioridade, neste trabalho, ao tratamento de princípios genuinamente jurídicos. Seja porque foram promulgados em legislação constitucional ou ordinária, ou porque foram recepcionados como válidos e obrigatórios através de critérios normais de reconhecimento. Contudo, como observado anteriormente, existe uma "terra incognita intermediária em que os princípios lutam pelo reconhecimento jurídico", em que existem princípios morais ou políticos que, ao servirem como elementos de racionalização de conjuntos normativos não ingressam, necessariamente, no ordenamento jurídico (MACCORMICK, 2009, p. 311).

18 “(a) casos em que não há nenhuma solução clara nos materiais jurídicos relevantes e (b) casos em que a solução que pode ser claramente inferida de alguma parte do mateirual jurídico relevante não pode ser justificada a partir de uma explicação coerente da totalidade do material jurídico relevante. Em ambos os casos trata-se daquilo que a
} 
parece não ter solução clara, uma forma de justificar essa solução deverá contemplar a coerência dessa solução. Ora, mesmo um legislador, que respeite o Estado de Direito, não deveria exercer o poder legislativo de forma arbitrária, sem considerar o modo pelo qual novas leis se sustentam dentro desse sistema jurídico como todo (MACCORMICK, 2008, p. 261).

A coerência se conforma a uma certa racionalidade da vida prática, exigente de universalidade e generalidade. Enquanto coerente, são maiores as chances de que o Direito seja inteligível em seus efeitos e previsível em sua aplicação. Para tanto, devendo ser representado por uma série razoavelmente pequena de princípios gerais que possam ser concebidos como parte do senso comum de uma comunidade (MACCORMICK, 2008, p. 263).

É bem verdade que a coerência não faz (de forma autônoma) com que o direito garanta justiça substancial, mas ainda assim é preferível o direito coerente ao incoerente, e o mesmo vale para as interpretações. A coerência age como constrangimento para que os juízes não imponham/criem normas se não sejam deriváveis do sistema existente, para que não exerçam o poder judicial em julgamentos de moralidade pessoal ou de justiça substantiva, senão aquela respaldada pela lei. É importante observar: uma decisão justa (coisa sujeita a controvérsia) não derivada do sistema existente pode até ser desejável, mas deverá se valer de outros tipos argumentativos, pois a coerência está contra ela. $\mathrm{Na}$ generalidade dos casos, os julgadores deveriam respeitar essa exigência negativa que faz a coerência. (MACCORMICK, 2008, p. 264266).

\subsubsection{A coerência é justificada sem uma teoria da razão prática?}

Como todas as formas de arrazoamento, existe um ponto sensível sobre a legitimidade, ou sobre a possibilidade, de se justificar uma argumentação com base na coerência. Michelon aponta uma crítica feita por Joseph Raz, à argumentação com base na coerência. Em seus fundamentos, sustenta que: (a) os atos legislativos de instituição de normas são legítimos e podem, legitimamente, pôr no sistema normas incoerentes, mas capazes de orientar a razão

tradição chama de "lacunas"” (MICHELON, 2009, p. 9). MacCormick vale-se de outra explicação para o fenômeno, observando que falar da existência de uma lacuna sugere que deveria haver uma disposição jurídica lidando com a questão de certo modo (a preencher a lacuna), uma conclusão sobre o que deveria ser feito, sem para tanto se apresentar motivos (uma argumentação consequencialista se ocupará dessa tarefa). Alternativamente, uma lacuna pode significar uma situação coberta por um princípio (estabelecido ou novo) mas a que as regras específicas (cobertas por esse princípio) não cubram (MACCORMICK, 2008, p. 270). 
prática, sem apelo a valores morais. Ou ainda, (b) essas normas podem se basear em diferentes valores (incoerentes, portanto). Obedecer a essa legislação, em termos morais (e democráticos) seria justificado (MICHELON, 2009, p. 24-25).

A resposta de Michelon, que busca repelir a crítica de Raz, é que, ao contrário do que se assume acima, a razão prática pressupõe coerência. A coerência, como essencial à razão prática, pode ser necessária por uma exigência de justiça (não arbitrariedade) ou pela eficiência na identificação de orientações para a ação. Seu argumento de resistência é completo pela afirmação substancial de que a vida humana se encerra em uma concepção aceitável do bem, e a realização da coerência se opera como uma forma de realização humana (MICHELON, 2009, p. 26-28).

Nesse ponto, Michelon parece estar assumindo, ainda que implicitamente, uma teoria da razão prática que justifique a coerência, por exigi-la. E se normas incoerentes, segundo Michelon, não servem à razão prática e, por consequência, para orientar a ação humana, "devemos concluir que a autoridade política que cria um direito incoerente dificilmente poderia ser considerada como uma autoridade legítima do ponto de vista moral” (MICHELON, 2009, p. 29).

Não se discorda que é mais desejável uma legislação coerente do que uma incoerente (MACCORMICK, 2008, p. 265), e que o direito inteligível pela coerência possa ser melhor para orientar a ação humana (MACCORMICK, 2008, p. 265). Assume-se, inclusive, que legisladores deveriam, em uma normalidade das situações, exercer o poder legislativo de forma coerente (MACCORMICK, 2008, p. 261). Contudo, lembra-se: a coerência sozinha não promove justiça substancial e se, em alguma medida, e sob robusta argumentação consequencialista, se aceitar a legitimidade judicial para empregar outras formas argumentativas senão as sistêmicas de coerência (MACCORMICK, 2008, p. 264-266), parece incoerente ${ }^{19}$ que legisladores não possam legislar com as mesmas justificativas.

O legislador pode, valendo-se de motivos legítimos ${ }^{20}$ (dois ou mais princípios incoerentes entre si em um contexto, ou buscando atender a algum critério utilitarista) promulgar normas que regularão condutas de forma aparentemente arbitrária. Esse tipo de regra, segundo Schauer,

\footnotetext{
${ }^{19}$ Se alguém tem legitimidade para criar normas não necessariamente deriváveis do sistema através de critérios de coerência, esse "alguém" deveria ser o ente legislativo. Nesse caso, permanecem as exigências de consistência, e a necessidade de certa justificação (de outra espécie, não fundada em coerência) adicional.

${ }^{20}$ Afirmar a ilegitimidade aqui, como faz Michelon, implica assumir e endossar uma teoria da razão prática com certos standards bem definidos de moralidade legislativa que coíbam a legislação contingencial ou utilitária.
} 
deveria ser reconhecida e aplicada pelos juízes (SCHAUER, 2009, p. 318-319), sob pena de se destinar ao judiciário o papel de decidir quando a lei é boa ou ruim.

A resposta de Michelon é, a este trabalho, mais atraente do que a alternativa, de se reconhecer como legítima uma legislação potencialmente utilitarista e arbitrária. Mas essa análise de legitimidade e, da mesma forma, do reconhecimento do poder de justificação do argumento de coerência, se dá em um plano de moralidade política (coerência legislativa) e de racionalidade prática (exigibilidade da coerência para a ação, ou para a boa ação). Uma teoria do direito que não assuma ou endosse pelo menos uma versão de teoria da justiça e teoria da razão prática não pode, por seus próprios meios, negar essa legitimidade legislativa ou justificar a exigibilidade de coerência.

\subsection{PRINCÍPIOS E ANALOGIAS}

Nos títulos 2 e 3 deste artigo foi feita uma apresentação descritiva dos princípios jurídicos, em contraste com as regras, da mesma forma quanto a critérios para sua identificação. No campo da argumentação jurídica, contudo, como observado anteriormente, eles assumem uma função específica (racionalizadora), que será o objeto primordial dessa abordagem, que será (funcionalmente) indissociável das noções de coerência e analogia.

A coerência foi apresentada como exigindo que as numerosas normas de um sistema jurídico desenvolvido deveriam "fazer sentido", quando consideradas em conjunto, e que essa compatibilidade se dá quando elas podem ser consideradas manifestações mais específicas ou concretas de uma norma geral (princípio). Assim, são de fundamental importância os argumentos formados a partir de princípios gerais do direito na argumentação jurídica. (MACCORMICK, 2009, p. 197-199).

Chamar uma norma de princípio (descritivamente) envolve reconhecê-la como geral e como dotada de valor positivo, racionalizador, capaz de justificar e explanar normas e decisões particulares. Do ponto de vista interno, a formulação de princípios denota uma tentativa de se entender os valores aos quais supostamente segue a legislação, atribuindo-lhe coerência. A argumentação por analogia, adianta-se, deve ser compreendida de forma semelhante, pois seu emprego no preenchimento de lacunas é uma espécie de argumentação pertencente à coerência.

Isso acontece porque decifrar a semelhança entre dois casos (analogia) é formular um

Revista de Teorias da Justiça, da Decisão e da Argumentação Jurídical e-SSN: 2525-9644|Curitiba|v.2 |n. 2|p.133-157| Jul/Dez. 2016. 
princípio jurídico, através de argumentação indutiva. Isto é: a argumentação de princípio, que pressupõe o pensamento analógico, induz à identificação da semelhança. Por sua vez, a relevância da analogia é testada pela análise de aplicabilidade de um princípio a ambos os casos. (MACCORMICK, 2008, p. 270-272).

A sujeição desses princípios a critérios comuns de reconhecimento é o que fornece a eles o seu status jurídico. Nesse sentido, os princípios jurídicos estão sujeitos a regras secundárias de alteração (e de promulgação) na mesma medida em que as demais normas do sistema. (MACCORMICK, 2009, p. 199-201).

Como observado anteriormente, no entanto, nem sempre os princípios formulados estão contidos no material jurídico existente, e tampouco é clara a sua exata intenção para cada caso concreto. Diversamente, eles são expressões de valores (e o meio para buscá-los), e seu sentido enquanto critérios de racionalização, isto é, o valor que eles apontam, é uma questão contestável. O caráter de ampla generalidade dos princípios oferece muita flexibilidade e possibilidade de abertura (MACCORMICK, 2009, p. 201). Essa abertura possibilita que, nas hipóteses de insuficiência do regramento existente, em que se invoque a explicação do regramento através de princípios, poderão surgir duas (ou mais) explicações concorrentes, e incompatíveis, dos materiais jurídicos relevantes (MICHELON, 2009, p. 10).

\subsubsection{Conflitos entre princípios}

Em contraste com os conflitos normativos entre regras (que se dá de forma disjuntiva: ou se aplica, ou não se aplica a regra), Dworkin propõe que os princípios, em casos de aplicação conflituosa, devem ser aplicados com o emprego de sua dimensão de peso, ou importância, sua força relativa, em que o que possuir menos "peso", para o caso, não fica invalidado. (DWORKIN, 2002, p. 42).

Michelon sugere três formas de se lidar com o conflito entre princípios: (a) o aprofundamento da análise de qual princípio explica melhor o material jurídico relevante para o caso, verificando-se qual melhor atende às exigências de coerência; (b) a hierarquização abstrata de princípios, mais plausivelmente imaginada pela hierarquia entre princípios constitucionais e infraconstitucionais; e (c) o sopesamento ou ponderação. (MICHELON, 2009,p. 10-12). 
A ponderação é sujeita a críticas, não apenas porque parece uma espécie qualificada de hesitação entre duas boas razões para resolver o problema, mas pela falta de standards de racionalidade que orientem o sopesamento, já que se trata de uma comparação entre dois princípios sem uma unidade de medida comum $^{21}$. Uma forma de lidar com esse problema é vinculando a ponderação às particularidades do caso concreto (e das soluções possíveis) ${ }^{22}$, para que sirvam como critérios, essa é justamente a diferença entre juiz e legislador na emissão de um comando. Nesse sentido, se fala de proporcionalidade, que mede a congruência entre os materiais jurídicos e a solução do caso concreto de três maneiras: proporcionalidade-adequação, proporcionalidade-necessidade e proporcionalidade em sentido estrito. (MICHELON, 2009, p. 13-17).

A proporcionalidade-adequação implica identificar a compatibilidade/incompatibilidade entre a solução analisada e os valores que justificam o conjunto de materiais jurídicos relevantes. A proporcionalidade-necessidade procura verificar a necessidade de que, para garantir a preservação de um princípio, outro seja violado. Como identificado por Michelon, essas duas formas de proporcionalidade não vão além da identificação da solução mais coerente, e de fato orientam-se por argumentos de coerência. (MICHELON, 2009, p. 16-18).

A proporcionalidade em sentido estrito, por sua vez, consiste em uma análise dos graus de violação de um princípio para a preservação de outro, em uma dada situação de fato. Isto é, uma análise das consequências jurídicas de uma dada solução conforme a aplicação dos princípios em questão e diante das circunstâncias do caso concreto (ALEXY, 2008, p. 98). Podese dizer que, na solução do conflito entre princípios através de ponderação, de um lado estarão argumentos sobre a coerência de uma solução em face do ordenamento jurídico, enquanto, de outro, argumentos sobre as consequências jurídicas de determinada solução.

Michelon levanta aí uma crítica à legitimidade dos argumentos de proporcionalidade (em sentido estrito), sugerindo que, enquanto a argumentação sobre a coerência goza da legitimidade de extrair soluções razoável e objetivamente obedientes às decisões políticas tomadas pela comunidade (direito existente), a proporcionalidade em sentido estrito não reconduz a essas decisões no momento da ponderação. Assim, os argumentos de coerência ancoram as soluções baseadas em princípios ao ordenamento jurídico, a ponderação em sentido estrito, por outro lado,

\footnotetext{
${ }^{21}$ “Esses interesses não têm um peso quantificável”. (ALEXY, 2008, p. 97)

${ }^{22 ، " E m ~ u m ~ c a s o ~ c o n c r e t o, ~ o ~ p r i n c i ́ p i o ~} \mathrm{P}_{1}$ tem um peso maior que o princípio colidente $\mathrm{P} 2$ se houver razões suficientes para que $\mathrm{P}_{1}$ prevaleça sobre $\mathrm{P}_{2}$ sob as condições C, presentes nesse caso concreto"(ALEXY, 2008,p. 97).
} 
não é dotada dessa racionalidade intrínseca. Sugere, nesse diapasão, que "talvez seja mais sábio restringir a argumentação jurídica por princípios a argumentos por coerência” (ALEXY, 2008, p. 98).

Enquanto se fala de critérios, de aplicação de princípios, que respeitem a autoridade legislativa pela direta recondução de sua função racionalizadora ao direito democraticamente estabelecido, parece que é impossível fugir da afirmação de Michelon, segundo a qual a proporcionalidade em sentido estrito outorga ao juiz um poder ilegítimo, pois, ao invés de reconduzir a aplicação dos princípios ao direito posto, estabelece como critério a análise de consequências da decisão.

Poder-se-ia argumentar, como um afunilamento para esse raciocínio a remissão da análise de consequências ao valor axiológico das normas como todo, do ordenamento jurídico, e de valores positivados no ordenamento através de disposições constitucionais fundamentais e outras solidamente estabelecidas como jurídicas. Nesse caso, a análise de consequências poderia voltarse à análise de possível violação/preservação desses valores.

Uma vez que trata-se de uma análise posterior às verificações mais diretas de coerência, não se pode vencer o argumento do autor que, nesse caso, se estaria outorgando ao juiz um poder de analisar consequências.

O apelo argumentativo da remissão a valores básicos do ordenamento, apesar disso, repousa em dois aspectos: (a) foram esgotados os esforços argumentativos de identificação do princípio jurídico compatíveis com a questão de forma hierarquicamente ordenada, não podendo essa coerência ser atropelada pelo critério remanescente (ponderação stricto senso); e (b) a remissão a valores base, por tratar-se de questão com amplo espectro interpretativo e, portanto, capaz de comportar amplas e irremediáveis discordâncias, deverá ser garantida por uma maioria autorizada (normalmente, um tribunal com um número ímpar de julgadores ou outra forma de decidir empates).

\subsection{PRINCÍPIOS E ANALOGIAS SÃo REALMENTE DIFERENTES?}

MacCormick sugere que a distinção entre regras e princípios seja supervalorizada. 
Afirma, portanto, que a "dimensão de peso"23 não é exclusiva aos princípios e que a solução dos conflitos de princípios e analogias se dão de forma bastante similar: isto é, analogias em competição também envolvem normas que puxam em direções distintas, em um contexto de aplicação ao caso concreto (MACCORMICK, 2009, p. 201-202).

Ora, os princípios de direito são normas compulsórias que, individualmente, tendem a garantir (ou têm o objetivo de garantir) algum fim que se considera valioso ou desejável, e permitem que se veja as leis como um conjunto coerente de normas destinadas a garantir objetivos gerais e, assim, agem como elemento para racionalizar as normas (MACCORMICK, 2009, p. 202-203). As analogias, por sua vez, são concretizações de um princípio em comum com o conjunto de normas relevante para o caso concreto. Quando se postula a semelhança entre dois casos, simultaneamente se postula a existência de um princípio que permite tomar emprestada a interpretação do direito, de um caso, para o outro. Princípios jurídicos (aqueles atingidos pela tese de validade), assim, servem para justificar juridicamente que a analogia postulada é uma concretização desse princípio (MACCORMICK, 2008, p. 272-275).

Em suma, solucionar um conflito de analogias envolve solucionar um conflito entre princípios, e concluir que uma analogia guarda relevante semelhança com o caso concreto implica concluir que existe um princípio que rege (ou deve reger) ambas as situações, porque "a pertinência da analogia depende da percepção de um princípio racional dentro do qual os dois itens comparados possam ser enquadrados", senda em que analogia se aplica como identificação de um princípio racionalizador do direito (MACCORMICK, 2009, p. 210).

\subsection{A APLICAÇÃO DE PRINCÍPIOS SE JUSTIFICA?}

Princípios, portanto, expressam valores que se deseja alcançar, e sua observância constitui-se como meio para alcançar esses valores. Assim, partes que queiram justificar determinados posicionamentos, analogias, ou interpretações, procurarão demonstrar que estão respaldadas por determinado princípio jurídico. Esse esforço de formular um princípio racionalizante, que cubra determinada área do direito e que seja um princípio do direito é o que

\footnotetext{
${ }^{23} \mathrm{Na}$ verdade, peso pode não ser a melhor forma de definir a importância dos princípios em um caso concreto, pois é uma metáfora que toma como base uma medida objetivamente mensurável. (MACCORMICK, 2009, p. 202).
} 
legitima uma decisão enquanto jurídica (MACCORMICK, 2009, p. 208).

Mas o que justifica a formulação de um princípio, e não outro? Sem dúvidas o próprio princípio não é conclusivo em si, e não autoproclama sua prioridade (MACCORMICK, 2009, p. 209). Esse parece ser o caso de uma colisão entre princípios, mas entre dois princípios de coerência razoavelmente equivalente, como pode ser justificada a escolha de um princípio senão pela aludida "ponderação em sentido estrito"? Essa pergunta ainda pode ser formulada de outra forma, que melhor denuncia o problema: uma vez identificados o princípio jurídico (ou os princípios jurídicos) subjacentes a um conjunto de regras, e a sua pertinência, como se pode saber se cada solução proposta dará eficácia ao princípio, ou alcançará os objetivos preconizados por ele e pelo ordenamento jurídico de que ele é parte coerente?

A solução para essa questão não está nos princípios, mas sim em uma análise das possíveis consequências das soluções apresentadas, que não pode ser feita em abstrato, aí incluída a análise da lealdade das possíveis consequências decisórias ao próprio princípio jurídico em questão. Se pode afirmar, com alguma segurança, que a adoção de princípios jurídicos e a sua respectiva aplicação não está justificada em si, mas somente diante da verificação (ainda que hipotética) de que a decisão em análise é capaz de gerar eficácia ao princípio jurídico invocado.

\section{CONCLUSÃO}

Cumpre ao propósito do artigo, portanto, sumarizar de forma conclusiva o apanhado expositivo desenvolvido, apresentando-se aqui um resultado à proposta inicial de "verificar uma forma de atribuir racionalidade à aplicação de princípios jurídicos - respeitando-se a autoridade legislativa".

O primeiro passo da sugestão presentada está na adequada identificação e delimitação do princípio jurídico. No escopo deste trabalho, trata-se de um standard mais geral que a regra, capaz de explicar a função de outras normas ou conjuntos normativos - esse aspecto racionalizador é o essencial para a sua aplicação no corpo de uma argumentação coerente e para 
a sua identificação como um princípio jurídico (em detrimento de um moral/político).

Como espécie do gênero sistêmico, a argumentação com o emprego de princípios jurídicos lança mão do caráter racionalizador para, nos eventos de indeterminação normativa das regras, derivar - do ordenamento jurídico - decisões compatíveis com o ordenamento visto como um todo coerente. Percebe-se, nessa ótica, que identificar uma analogia é identificar uma unidade de princípio entre um caso paradigma e o caso que se busca decidir, é demonstrar que faria sentido que o caso em análise seguisse o mesmo critério, ou mesmo standard de outro caso, pois sobre eles incidem o mesmo princípio.

Apesar dos critérios comuns de coerência para identificar possíveis decisões discrepantes e/ou compatíveis com o ordenamento, é possível que um intérprete, jurista ou julgador se depare com a situação em que dois princípios possam parecer adequar-se à situação concreta, com desfechos dissidentes. Ou ainda, que o caso concreto possa guardar muitas semelhanças, individualmente, com dois um mais casos distintos aos quais foram dadas respostas diferentes, e ambos venham a ser cogitados como analogias compatíveis para a solução do caso. O que caracterizaria um conflito.

Nas circunstâncias conflituosas, existe uma cadeia coordenada de critérios de racionalidade da qual se busca extrair uma resposta coerente com o ordenamento jurídico. Busca-se o aprofundamento cognitivo do caráter racionalizador dos princípios quanto ao material jurídico que se busca explicar - isto é, qual princípio explica de forma mais coerente o direito para o problema -; da mesma forma, busca-se estabelecer qual princípio ou conjunto de princípios deve, por critérios comuns e abstratos, prevalecer hierarquicamente em face de outros - isto é, estabelecer quais princípios deverão prevalecer em face de outros, e em qual medida, para que o ordenamento faça sentido -; desse ponto, se esgotados os esforços anteriores e ainda assim restar dúvida significativa, aí sim o julgador/intérprete poderá recorrer à análise das consequências projetadas de uma decisão - aí sim, residualmente, através de forma análoga à ponderação stricto senso. As consequências a serem avaliadas, contudo, são na escala de preservação de eficácia do princípio que se pretende ver veiculado e, progressivamente, até os valores base do ordenamento. Fazê-lo em ordem diversa equivaleria a submeter a autoridade legislativa à eleição de valores relevantes por parte de cada juiz solipsista.

Por fim, é importante que se perceba o limite da argumentação com base em princípios jurídicos, a escolha entre dois princípios não encontra justificativa no âmbito dos princípios 
jurídicos, mas apenas externamente. Isto é, deve haver sempre uma justificativa externa ao princípio para justificar a sua escolha em detrimento de outro.

Uma vez que essa justificativa frequentemente repousa no seio de uma teoria da justiça, da razão prática e/ou com seu objeto fundamental além de uma teoria pretensamente neutra do direito, capaz de suscitar muitas dúvidas e irremediáveis discordâncias, é fundamental que, nesse nível de argumentação escalonada, persistindo a divergência - muitas vezes sem que haja uma decisão óbvia ou aparentemente errada -, as decisões sejam tomadas por uma maioria autorizada.

Com esses critérios, então, é possível empregar princípios jurídicos de maneira a: (a) identificar os princípios jurídicos, utilizando-se critérios comuns de reconhecimento e resguardando alguma autonomia do direito em relação às esferas moral e política (b) mitigar a discricionariedade diante dos casos de indeterminação normativa; (c) fazê-lo de forma razoavelmente leal ao direito democraticamente posto como um todo coerente; (d) subjugar o ativismo inerente às decisões (políticas) em que as consequências ponderadas pelo juízo vão além do respeito ao direito positivo; (e) posicionar os princípios em relação às analogias e situálos entre os demais argumentos calcados na coerência; e, por derradeiro, (f) verificar os limites da argumentação fundada em princípios jurídicos - ponto em que se demanda uma justificativa de ordem externa.

\section{BIBLIOGRAFIA}

ALEXY, Robert. Teoria dos Direitos Fundamentais. São Paulo: Malheiros, 2008.

ALVAREZ, Alejandro. Interpretação do Direito e Equidade. Porto Alegre: UFRGS, 2015.

BARZOTTO, Luis Fernando. Filosofia do Direito: os conceitos fundamentais e a tradição jusnaturalista. Porto Alegre: Livraria do Advogado, 2010.

O Positivismo Jurídico Contemporâneo: uma introdução a Kelsen, Ross e Hart. São Leopoldo: UNISINOS, 1999. 
DWORKIN, Ronald. Levando os Direito a Sério. São Paulo: Martins Fontes, 2002.

O Império do Direito. São Paulo: Martins Fontes, 2010.

FARIA, Paulo. Prefacio a Claudio Fortunato Michelon Jr., 'Aceitação e Objetividade'. São Paulo, 2004.

HART, Herbert L. A. O Conceito de Direito. 3. ed. Lisboa: Fundação Calouste Gulbenkian, 1994.

KELSEN, Hans. Teoria Pura do Direito. Coimbra: Armenio Amado, 1984.

Teoria Pura do Direito. São Paulo: Martins Fontes, 2009.

LORENZETTI, Ricardo Luis. Teoria da Decisão Judicial: fundamentos de Direito. São Paulo: Revista dos Tribunais, 2011.

MACCORMICK, Neil. H. L. A. Hart. São Paulo: Elsevier, 2010.

Retórica e o Estado de Direito. Rio de Janeiro: Elsevier, 2008.

Argumentação Jurídica e Teoria do Direito. São Paulo: Martins Fontes, 2009.

MICHELON, Claudio. Aceitação e Objetividade: uma comparação entre as teses de Hart e do positivismo precedente sobre a linguagem e o conhecimento do Direito. São Paulo: Revista dos Tribunais, 2004. 
But to live inside the law, you must be honest. Research Paper Series, n. 2, 2013.

. MacCormick's institutionalism between theoretical and practical reason. Working Paper Series. N. 12, 2010.

. Practical wisdom in legal decision-making. Working Paper Series. n. 13, 2010.

. Princípios e coerência na argumentação jurídica. Working Paper Series. n. 8, 2009.

MOTTA, Francisco José Borges. Ronald Dworkin e a Construção de uma Teoria Hermeneuticamente Adequada da Decisão Jurídica Democrática. 2014. 290 f. Tese (Doutorado em Direito Público) - UNISINOS, São Leopoldo, 2014.

RICOUR, Paul. O Justo. São Paulo: Martins Fontes, 2008. v. 1.

SCHAUER, Frederick. Rules, rationality, and the significance of standpoint. Queen's Law Journal, v. 35, p. 305-325, 2009.

STRECK, Lenio Luiz. Aplicar a "Letra da Lei" é uma atitude positivista? Revista Novos Estudos Jurídicos, n. 1, v. 15, p. 158-173, jan./abr. 2010.

Hermenêutica e (pós)positivismo: por que o ensino jurídico continua de(sin)formando os alunos? In: CALLEGARI, André Luís; STRECK, Lenio Luiz; ROCHA, Leonel Severo. Constituição, Sistemas Sociais e Hermenêutica. Porto Alegre: Livraria do Advogado, 2010. p. 163-186.

Verdade e Consenso: constituição, hermenêutica e teorias discursivas. 5. ed. São Paulo: Saraiva, 2014. 
WILSON, Engelmann. 2001. Crítica ao Positivismo Jurídico: princípios, regras e o Conceito de Direito. Porto Alegre: Sergio Antônio Fabris, 2001. 